\title{
Main and interactive effects of shiftwork, age and work stress on health in an Italian sample of healthcare workers
}

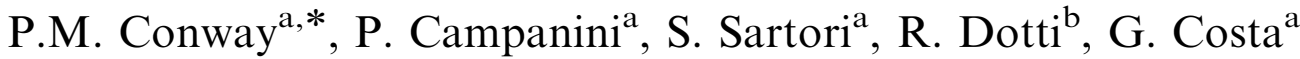 \\ ${ }^{a}$ Department of Occupational Health, University of Milan and IRCCS Maggiore Hospital, Mangiagalli and Regina Elena Foundation, \\ via San Barnaba 8, 20122 Milan, Italy \\ ${ }^{\mathrm{b}}$ Nursing Service, "Carlo Poma" Community Hospital, Mantua, Italy
}

Received 28 September 2007; accepted 16 January 2008

\begin{abstract}
Among healthcare workers, shiftwork (mostly if nightwork is also included), ageing and work-related stress may be factors leading to impaired health. Such risk factors may also operate in interaction, resulting in an even increased harm for health. The present study aims at evaluating these relationships in a sample of 1842 hospital workers in Northern Italy. Subjects were mainly women, 33.1\% were aged $\geqslant 45 \mathrm{yr}$, and they were almost evenly distributed between dayworkers and rotating shiftworkers (nights included). Shiftwork was associated with poor sleep, while it was protective against gastrointestinal disorders, poor work ability and job dissatisfaction. Work stress was the risk factor with the highest relevance for poor health. Ageing was associated with lower physical health. Few significant interactions were observed. Shiftwork with nights and high work stress significantly interacted in increasing the risk for poor sleep. The "healthy worker effect" may have played a strong role in study findings.
\end{abstract}

(C) 2008 Elsevier Ltd. All rights reserved.

Keywords: Shiftwork; Work stress; Healthcare workers; Ageing

\section{Introduction}

\subsection{Shiftwork and work-related stress}

Shiftwork and work-related stress are important topics in the healthcare sector due to their possible negative impact on workers' health and safety. This includes cardiovascular disease, gastrointestinal complaints, sleep troubles, mental health problems, fatigue, job dissatisfaction, accidents and injuries at work, reduced vigilance and job performance, absenteeism and turnover (Muecke, 2005; Poissonnet and Véron, 2000; McVicar, 2003).

The negative effects of shiftwork derive basically from an inadequate biopsycho-social adaptation to the temporal challenges posed by working on rotating shift work (Costa and Sartori, 2007). Indeed, shiftwork may cause disturbances to circadian rhythms (e.g. sleeping/wake cycle) and to psychological health through fatigue and disruption to

\footnotetext{
*Corresponding author. Tel.: + 390250320112.

E-mail address: paul.conway@unimi.it (P.M. Conway).
}

social/family life. Prolonged exposure and ineffective coping resources to shiftwork may result in adverse health effects (Olsson et al., 1990). The role of cognitive appraisals and coping as variables that mediate the relationship between shiftwork and health has been increasingly recognized (Haider et al., 1981; Monk, 1988; Olsson et al., 1990; Taylor et al., 1997). According to Taylor et al. (1997, p. 74), the "movement from a linear, chronobiological conceptualization toward more conceptually broad, dynamic, multidirectional, psychological view of the relationship between shiftwork and health", was mainly supported by the observation that variations in adaptation to shiftwork can not be fully explained by factors such as the shift system, biological disturbances and stable individual differences.

Coping is also central to the transactional model of stress developed by Lazarus and Folkman (1984). This model posits that the effect of a potential stressor on health and well-being depends upon cognitive processes, whereby individual appraisals are essential in determining the degree to which a potential stressor will be perceived as 
threatening (primary appraisal) and in shaping people's judgements about resources available to cope (secondary appraisal). As a result of these appraisals, the individual will enact specific coping strategies to deal with the potential source(s) of stress. The choice of coping strategies depends upon several factors, attributable to both the individual (e.g. age, gender, personality type) and the situation (quality of work life, support from the external social environment). Similarly, the effect of shiftwork on health may be viewed in a transactional perspective. As any other stressor, the experience of shiftwork elicits appraisals and coping responses that influence the way an employee will respond (Taylor et al., 1997; Olsson et al., 1990; Smith et al., 1999).

Apart from their common link with coping, the similarity between shiftwork and other sources of stress at work is also suggested by the relationship they share with health outcomes typically associated with stress (Taylor et al., 1997; Härmä, 2006). It seems that shiftwork and stress both show similar physiopathological pathways in the way they affect health status. For example, Härmä (2006) has reported evidence that inadequate recovery from short or disturbed sleep is a common pathway linking shiftwork and work stress with cardiovascular diseases. In addition, shiftwork and work-related stress may both interfere with the quality of social and family life. Shiftwork and in particular, schedules that involve nightwork, may limit both the quantity and quality of time spent with the family and involvement in social activities (Demerouti et al., 2004). Similarly, work stress may reduce social contacts as individuals fail to unwind and detach themselves from their work problems (Simon et al., 2004).

These similarities may stimulate research over the possible interaction existing between shiftwork and work-related stress in affecting health and well-being. While this topic has been addressed by some authors (Peter et al., 1999; Parkes, 1999; Frese and Semmer, 1986), research on the interaction between shiftwork and work stress has been limited and interactions have not always been tested using established statistical procedures. Therefore, in this study we aim to evaluate not only the association between shiftwork, work stress and health, but also the combined impact of shiftwork and work stress on health. This "additive" approach is recommended when the synergy between two risk factors is tested by means of binomial logistic regression models (Hallqvist et al., 1996).

On the basis of these considerations, three study hypotheses were formulated (note that specific indicators of poor health included in this study are listed only in H1a, but they do not differ in the other study hypotheses, with the only exception of $\mathrm{H} 3 \mathrm{a}$, see below):

H1a. Shiftwork with nights, as compared with daywork, is associated with a higher risk for poor health (as assessed by the following indicators: poor work ability, poor sleep, chronic fatigue, injuries, cardiovascular, gastrointestinal, musculoskeletal and mental disorders, absenteeism and job dissatisfaction);
H1b. Work stress (in terms of high effort/reward imbalance) is associated with a higher risk for poor health;

H1c. (interaction). The combined exposure to shiftwork with nights and work stress is associated with a risk for poor health that is significantly higher than the risk associated with their additive effect.

\subsection{Effort/reward imbalance and overcommitment}

Work stress will be operationalized in this study through the effort/reward imbalance model (Siegrist and Peter, 1996). This model, based on equity theory (Adams, 1965), assumes that stress emerges when efforts spent at work are not reciprocated by rewards which may be financial and non-financial. Over time the imbalance between efforts and rewards may increase susceptibility to illness thorough continuous experience of negative emotions and consequent strain (Siegrist et al., 2004). The effort/reward imbalance has proved effective in predicting several outcomes related to health and well-being (van Vegchel et al., 2005) among healthcare workers (van Vegchel et al., 2001; Hasselhorn et al., 2004; Bakker et al., 2000; Weyers et al., 2006). Moreover, according to the model there may also be individual differences in the experience of effort/ reward imbalance. In particular, "overcommitment" is characterized by a tendency to overestimate the efforts required and underestimate the rewards received, and is supposed to increase the health risk as a result of this imbalance. Accordingly, two further hypotheses were formulated in our study:

H2a. Overcommitment is associated with a higher risk for poor health;

H2b. (interaction). The combined exposure to high effort/ reward imbalance and high overcommitment is associated with a risk of poor health that is significantly higher than the risk associated with their additive effect.

\subsection{Ageing and shiftwork}

In the near future, the working population will age in industrialized countries and this creates a problem in terms of who cares for the elderly and the quality of this care (Costa and Sartori, 2007). An ageing population implies an increasing prevalence of chronic illnesses (Hasselhorn et al., 2003) and consequently, more healthcare staff will be needed to provide adequate care.

One way to meet this imbalance is to examine factors that will retain existing workers. Conway (2005) has demonstrated that the loss of healthcare staff in Italy has led to a decrease in the quantity and quality of care. To increase retention, organizations should explore strategies to maintain and improve working conditions (including shiftwork and psychosocial factors) and sustain healthcare workers' health and work ability as they age. Ageing is typically associated with decreased physical health, while 
the relationship between ageing and outcomes such as job satisfaction, absenteeism and injuries is more controversial, with studies indicating that being older may actually protect employees (Beatty and Burroughs, 1999; Ingersoll et al., 2002; Taimela et al., 2007).

Ageing may be also a factor increasing the adverse impact of shiftwork on health, as age is usually associated with an increased vulnerability to several factors. In particular, ageing is linked to a reduced flexibility in circadian adjustment and less-efficient sleep (Härmä, 1996; Costa, 2003; Costa et al., 2005). Accordingly, these two final study hypotheses were formulated:

H3a. Ageing is associated with a higher risk for poor health (poor work ability, poor sleep, chronic fatigue, cardiovascular, gastrointestinal, musculoskeletal and mental disorders);

H3b. (interaction). When combined, ageing ( $>45$ years old) and shiftwork with nights are associated with a risk of poor health that is significantly higher than the risk associated with their additive effect.

\subsection{Ageing, effort/reward imbalance and overcommitment}

Age may also be assumed to interact with work effort/ reward imbalance and overcommitment in influencing health status. One can assume that younger healthcare staff experience higher imbalance between efforts and rewards due to factors such as poor career possibilities, job insecurity and unsatisfactory pay. Older staff may also be at risk because they may find it more difficult to adapt to changing work demands and unstable work environments resulting from the cost-driven healthcare organizations and by continuous technological changes (Conway, 2005). Moreover, the impact of poor self-esteem in older workers as they usually rely more on supportive and collaborative work environments to sustain their performance (Ilmarinen, 1999). Finally, the adverse effect of overcommitment may be higher in younger workers, since, owing to their stage in the life cycle and the current conditions of the labour market, they may find themselves forced, to increase their efforts in the face of inadequate rewards. However, since the age implication of effort/reward imbalance and overcommitment has not drawn particular attention in the literature so far, no clear hypotheses can be stated concerning whether an interaction exists or the direction of this relationship. As a final aim we evaluate whether significant interactions exist between age and effort/reward imbalance, and age and overcommitment in their influence on several health outcomes.

\section{Methods}

\subsection{Sample and procedure}

A self-report questionnaire was distributed to 2412 nonmedical healthcare workers in seven state-owned and private hospitals in Northern Italy. Replies were received from 1842 workers $(76.4 \%)$. We retained those participants with valid values on gender, age and work schedule. The sample was composed mainly of women $(81.8 \%), 33.1 \%$ were aged $\geqslant 45 \mathrm{yr}$, with a mean job tenure of $13.2 \mathrm{yr}$ $(\mathrm{SD}= \pm 9.05$, range $1-40 \mathrm{yr})$. The majority were registered nurses $(61.7 \%)$, followed by assistant nurses $(23.1 \%)$ and the balance were rehabilitation staff and health technicians $(15.5 \%)$. Most were employed as dayworkers $(49.3 \%)$, $46.1 \%$ were shifworkers with nightwork and $4.6 \%$ worked on shifts without nightwork. This latter group was not used in the analysis due to their small number (final sample $=1754$ participants). The mean length of time as shiftworkers was $9.8 \mathrm{yr}(\mathrm{SD} \pm 9.40)$.

\subsection{Measures}

\subsubsection{Work schedule}

Participants were asked to report their shift schedules and these were categorized into: "daywork", "shiftwork including night shifts" and "shiftwork excluding night shifts" (not analysed). Day workers worked from 07:00-08:00 to 16:00-17:00. The rotating shiftworkers worked a fast forward rotation schedule: one morning (06:00-13:00), one afternoon (13:00-20:00) and one night shift (20:00-06:00) followed by 2 days off.

\subsubsection{Effort/reward imbalance}

Work stress was measured using the Effort Reward Imbalance Questionnaire (ERI-Q; Siegrist and Peter, 1996). The ERI-Q consists of 17 items; six-items measure "effort" and 11-items measure "reward". The "effort" component refers to individual stress experienced in relation to demanding aspects of the job (e.g. quantitative and qualitative demands). The participants rated the amount of distress experienced in relation to each work characteristic on a four-point scale ("not at all distressed" to "very distressed"). Cronbach's alpha for the effort and reward scale was 0.80 and 0.84 , respectively. The final score for ERI-Q was calculated based on the ratio between effort and reward. Reward was multiplied by a correction factor (0.55) to account for the different numbers of items in the numerator and the denominator. The ERI continuous score was categorized so that an ERI $>1$ indicated work stress since efforts are higher than rewards. An ERI $\leqslant 1$ describes a non-stressful situation.

\subsubsection{Overcommitment}

Overcommitment was measured using Siegrist's (1996) scale. The items measured four relevant aspects of overcommitment: "need for approval", "competitiveness and latent hostility", "impatience and disproportionate irritability" and "inability to withdraw from work obligations". The participants are asked to answer each item on a four-point agreement-disagreement scale. Cronbach's alpha for this scale was 0.71 . 


\subsubsection{Work ability index}

Perceived work ability was measured by the WAI (Tuomi et al., 1998). The WAI consists of seven items: (1) subjective estimation of current work ability compared with optimal lifetime performance; (2) subjective work ability in relation to physical and mental demand of work; (3) number of diseases for which a medical diagnosis has been given; (4) subjective estimation of working impairment because of ill health; (5) sickness absenteeism during the past year; (6) own prognosis of work ability after $2 \mathrm{yr}$; and (7) psychological resources.

The total WAI was calculated by summing the items and scores were categorized as: "poor" (7-27), "moderate" (28-36), "good" (37-43) or "excellent" (44-49). We combined the "poor" and "moderate" categories to represent low work ability. Cronbach's alpha for the WAI was 0.70 .

For item-3, answers were based on the following health outcomes: injury-related health consequences, gastrointestinal disorders, cardiovascular disorders, musculoskeletal disorders and mental disorders. For each outcome, participants were coded as ill only if the disorder was diagnosed by a physician. Days of sick-leave absence were determined by item number 5 of the WAI. Ten days of sickleave absence or more were considered as the risk category.

\subsubsection{Standard shiftwork index}

Measures for "poor sleep", "chronic fatigue" and "job dissatisfaction" were taken from the standard shiftwork index (Barton et al., 1995). Poor sleep was measured by one question asking about the quantity of sleep taken before the different shifts (morning, afternoon, night) and on rest days. Chronic fatigue was measured by a 10 -item scale. Half the items assessed vigour and energy, whilst the others measured general feelings of tiredness and lack of energy. Responses were made using a 5-point Likert scale ("not at all" to very much"). Job dissatisfaction was measured on a five-item scale and responses were given on a seven-point Likert scale ("strongly disagree" to "strongly agree"). For each scale scores were summed to give an overall measure, with higher scores indicating a less favourable condition. For inclusion in the logistic models, the continuous variables "poor sleep", "chronic fatigue" and "job dissatisfaction" were categorized at conservative cut-off points to identify groups of workers with a low health status. Cronbach's alpha for "poor sleep", "chronic fatigue" and "job dissatisfaction" was $0.65,0.89$ and 0.71 , respectively.

\subsection{Statistical analysis}

Several logistic regression analyses were conducted to test both crude and multivariate associations between the risk factors (work schedule, age, effort/reward imbalance and overcommitment) and the outcomes. In the multivariate models, the associations were adjusted for gender, family status, number of children, job title, smoking status, workload and all the other risk factors. Odds ratios (OR) were obtained with $95 \%$ confidence intervals (CI). OR were considered significant if $\mathrm{CI}$ did not include 1 .

Additive interactions were tested using Rothman's synergy index (Rothman, 1986). This index tests if the combined effect of two risk factors significantly departs from the additive effect of the two risk factors taken separately. We applied the formula provided by Kalilani and Atashili (2006) for use when OR instead of relative risks are available. A synergy index higher than 1 indicates synergism, while less than 1 indicates antagonism. To calculate the CI of the synergy index, we used the formula created by Hosmer and Lemeshow (1992). The index is considered to be significant if the CI does not cross the 1 . Statistical analyses were carried out using Stata 9. (StataCorp, 2005) and SPSS, 12.01.

\section{Results}

\subsection{Prevalence of study variables}

As shown in Table 1, $16.1 \%$ of the participants reported high effort/reward imbalance (scores $>1$ ), while $26.3 \%$ were in the highest overcommitment tertile. In our sample, $33.7 \%$ reported a poor or moderate WAI, and $26.4 \%$ had been on sick leave for 10 days or more during the previous 12 months. As for medically diagnosed illnesses, 39.9\% reported a musculoskeletal disorder, $25.3 \%$ an injuryrelated health consequence, $23.9 \%$ a gastrointestinal, $16.6 \%$ a cardiovascular and $6.2 \%$ a mental disorder. According to the conservative cut-off we applied, $22.4 \%$ reported high chronic fatigue, $15.8 \%$ a poor sleep and $10.3 \%$ job dissatisfaction.

\subsection{Associations between risk factors and health outcomes}

In Table 2, the (adjusted) associations between work schedule, age, effort/reward imbalance and overcommitment and several health outcomes are shown. Shiftwork with nights was significantly associated with a higher risk of poor sleep compared to daywork (OR 1.74, CI 1.18-2.56). Moreover, shiftwork with nights was significantly associated with a lower risk of job dissatisfaction, gastrointestinal disorders and poor/moderate WAI (OR ranging from 0.65 to 0.76 ). Thus, H1a was supported only in the case of poor sleep, while the other significant associations were in a direction contrary to that expected.

High effort/reward imbalance was significantly associated with a higher risk of job dissatisfaction, poor/ moderate WAI, mental disorders, poor sleep, chronic fatigue and sick leave (OR ranging from 1.52 to 3.71). High overcommitment was significantly associated with a higher risk of reporting poor sleep, injury-related health consequences, cardiovascular disorders, musculoskeletal disorders and poor/moderate WAI (OR ranging from 1.39 to 1.83). Thus, $\mathrm{H} 1 \mathrm{~b}$ and $\mathrm{H} 2 \mathrm{a}$ were the hypotheses receiving the strongest support in this study. 
Table 1

Sociodemographic, work-related and health characteristics of the study sample $(n=1754)$

\begin{tabular}{|c|c|c|c|c|c|}
\hline Variables & $N$ & $\%$ & Variables & $N$ & $\%$ \\
\hline Gender & & & Work ability & & \\
\hline Male & 320 & 18.2 & Poor-moderate & 576 & 33.7 \\
\hline Female & 1434 & 81.8 & Good-excellent & 1133 & 66.3 \\
\hline Age & & & Days on sick leave in the last year & & \\
\hline$<45$ & 1173 & 66.9 & Less than 10 days & 1261 & 73.6 \\
\hline$\geqslant 45$ & 581 & 33.1 & 10 days or more & 453 & 26.4 \\
\hline Marital status & & & Injury-related health consequences ${ }^{\mathrm{a}}$ & & \\
\hline Single & 329 & 18.8 & No medical diagnosis & 1311 & 74.7 \\
\hline Married/common-law husband or wife) & 1237 & 70.5 & Medical diagnosis & 443 & 25.3 \\
\hline Other (separated, divorced or widowed) & 188 & 10.7 & Gastrointestinal disorders & & \\
\hline Children & & & No medical diagnosis & 1334 & 76.1 \\
\hline None & 616 & 35.1 & Medical diagnosis & 420 & 23.9 \\
\hline One or more & 1138 & 64.9 & Cardiovascular disorders & & \\
\hline Smoking status & & & No medical diagnosis & 1463 & 83.4 \\
\hline No & 1237 & 72.1 & Medical diagnosis & 291 & 16.6 \\
\hline Yes & 479 & 27.9 & Musculoskeletal disorders & & \\
\hline Profession & & & No medical diagnosis & 1055 & 60.1 \\
\hline Registered nurse & 1082 & 61.7 & Medical diagnosis & 699 & 39.9 \\
\hline Assistant nurse & 406 & 23.1 & Mental problems & & \\
\hline Rehabilitation staff and health technician & 266 & 15.2 & No medical diagnosis & 1646 & 93.8 \\
\hline Work schedule & & & Medical diagnosis & 108 & 6.2 \\
\hline Daywork & 906 & 51.7 & Sleep & & \\
\hline Shiftwork with nights & 848 & 48.3 & Poor & 224 & 15.8 \\
\hline Efforts-reward imbalance & & & Good & 1195 & 84.2 \\
\hline Low imbalance $(\mathrm{ERI} \leqslant 1)$ & 1269 & 83.9 & Chronic fatigue & & \\
\hline High imbalance (ERI > 1) & 244 & 16.1 & Low & 1134 & 77.6 \\
\hline Overcommtiment & & & High & 327 & 22.4 \\
\hline Lower-medium tertile & 1293 & 73.7 & Job satisfaction & & \\
\hline Higher tertile & 461 & 26.3 & Low & 181 & 10.3 \\
\hline Workload & & & High & 1573 & 89.7 \\
\hline Lower tertile & 574 & 36.4 & & & \\
\hline Medium tertile & 572 & 36.2 & & & \\
\hline Higher tertile & 433 & 27.4 & & & \\
\hline
\end{tabular}

${ }^{\mathrm{a}}$ Injuries not only work-related.

Older healthcare staff (age $\geqslant 45 \mathrm{yr}$ ) had a significantly higher risk of reporting cardiovascular disorders, poor/ moderate WAI and musculoskeletal disorders (OR ranging from 1.39 to 3.62 ), which partially supports $\mathrm{H} 3 \mathrm{a}$.

As a whole, the amount of variance in the health outcomes was generally low $(0.03-0.12)$ using the Nagelkerke's pseudo- $R^{2}$ statistic. This statistic has a range $0-1$, with 1 indicating maximum variance explained.

\subsection{Interactions between risk factors}

In Table 3, we reported results concerning the adjusted interactions between the risk factors that in the previous logistic analyses were found to be significantly associated with the outcomes.

Healthcare staff with the combined exposure "shiftwork and high effort/reward imbalance" reported a significantly higher risk for poor sleep than the additive effects of the two risks taken separately (synergy index $=2.12$, CI 1.37-2.73), indicating synergism. Therefore, with the exception of poor sleep, as a whole the interaction hypothesis concerning shiftwork and work stress (H1c) was not supported. Those with both high effort/reward imbalance and high overcommitment reported a risk for poor/moderate WAI and poor sleep that was significantly lower than their additive effect, indicating antagonism between these factors (synergy index $=0.62$, CI $0.52-0.74$ and 0.70 , CI $0.56-0.88$, respectively). These two interactions were contrary to our hypothesis H2b. Finally, no significant interactions were observed between age and shiftwork (H3b), age and effort/reward imbalance, and between age and overcommitment.

\section{Discussion}

\subsection{Summary}

This study aimed at testing the hypothesis that shiftwork with nights, ageing, high effort/reward imbalance and high overcommitment are associated with several indicators of poor health. In summary, we found that, after adjustment for gender, family status, number of children, job title, 
Table 2

Associations between work, schedule, age, effort/reward imbalance and over commitment on health

\begin{tabular}{|c|c|c|c|c|c|c|c|c|c|c|}
\hline \multirow[t]{2}{*}{ Risk factors } & \multicolumn{2}{|c|}{ Poor/moderate WA } & \multicolumn{2}{|l|}{ Poor sleep } & \multicolumn{2}{|l|}{ Chronic fatigue } & \multicolumn{2}{|l|}{ Job dissatisfaction } & \multicolumn{2}{|l|}{ Sick leave } \\
\hline & Crude OR & Adjusted $\mathrm{OR}^{\mathrm{a}}$ & Crude OR & Adjusted $\mathrm{OR}^{\mathrm{a}}$ & Crude OR & Adjusted $\mathrm{OR}^{\mathrm{a}}$ & Crude OR & Adjusted OR & Crude $\mathrm{OR}^{\mathrm{a}}$ & Adjusted $\mathrm{OR}^{\mathrm{a}}$ \\
\hline $\begin{array}{l}\text { Shiftwork with nights } \\
\text { (ref. daywork }\end{array}$ & $0.73(0.58-0.91)$ & $0.76(0.58-0.99)$ & $1.77(1.26-2.48)$ & $1.74(1.18-2.56)$ & $0.86(0.66-1.12)$ & $0.81(0.59-1.10)$ & $0.89(64-1.25)$ & $0.65(0.44-0.97)$ & $0.80(0.63-1.03)$ & $0.82(0.62-1.1)$ \\
\hline$\geqslant 45 \mathrm{yr}$ (ref. $<45 \mathrm{yr})$ & $1.35(1.05-1.72)$ & $1.39(1.06-1.82)$ & $0.85(.59-1.21)$ & $0.91(0.62-1.35)$ & $1.04(0.77-1.40)$ & $1.11(0.80-1.54)$ & $0.71(0.48-1.06)$ & $0.74(0.48-1.13)$ & $1.28(0.98-1.67)$ & $1.15(0.87-1.53)$ \\
\hline $\begin{array}{l}\text { High effort/reward } \\
\text { imbalance (ref. low) }\end{array}$ & $2.50(1.87-3.33)$ & $2.38(1.73-3.27)$ & $2.34(1.67-3.39)$ & $1.79(1.21-2.65)$ & $2.06(1.50-2.83)$ & $1.77(1.25-2.52)$ & $3.65(3.53-5.24)$ & $3.71(2.46-5.58)$ & $1.39(1.02-1.90)$ & $1.52(1.08-2.14)$ \\
\hline \multirow{3}{*}{$\begin{array}{l}\text { Overcommitment } \\
\text { higher tertile (ref. } \\
\text { lower-medium tertiles) }\end{array}$} & $1.66(1.29-2.12)$ & $1.39(1.07-1.81)$ & $2.09(1.51-2.88)$ & $1.83(1.30-2.58)$ & $2.01(1.552-2.67)$ & $1.73(0.96-1.87)$ & $1.72(1.21-2.44)$ & $1.40(0.96-2.03)$ & $1.19(0.91-1.56)$ & $1.10(0.83-1.47)$ \\
\hline & \multicolumn{2}{|c|}{$\begin{array}{l}\text { Injury-related health } \\
\text { consequences }\end{array}$} & \multicolumn{2}{|c|}{ Gastrointestinal disorders } & \multicolumn{2}{|c|}{ Cardiovascular disorders } & \multicolumn{2}{|c|}{ Musculoskeletal disorders } & \multicolumn{2}{|l|}{ Mental disorders } \\
\hline & Crude OR & Adjusted $\mathrm{OR}^{\mathrm{a}}$ & Crude OR & Adjusted $\mathrm{OR}^{\mathrm{a}}$ & Crude OR & Adjusted $\mathrm{OR}^{\mathrm{a}}$ & Crude OR & Adjusted $\mathrm{OR}^{\mathrm{a}}$ & Crude OR & Adjusted $\mathrm{OR}^{\mathrm{a}}$ \\
\hline $\begin{array}{l}\text { Shiftwork with nights } \\
\text { (ref. daywork }\end{array}$ & $1.0(0.79-1.27)$ & $0.93(0.70-1.22)$ & $0.72(57-92)$ & $0.75(0.57-99)$ & $0.68(0.51-91)$ & $0.82(0.59-1.16)$ & $0.71(0.57-0.88)$ & $0.85(0.66-1.09)$ & $0.68(0.43-1.07)$ & $0.66(0.40-1.10)$ \\
\hline$\geqslant 45 \mathrm{yr}($ ref. $<45 \mathrm{yr})$ & $1.31(1.01-1.169)$ & $1.20(0.91-1.59)$ & $1.25(0.96-1.62)$ & $1.24(0.94-1.65)$ & $3.79(2.81-5.12)$ & $3.62(2.62-5.00)$ & $1.66(1.32-2.10)$ & $1.58(1.22-2.04)$ & $1.17(0.72-1.89)$ & $1.09(.65-1.83)$ \\
\hline $\begin{array}{l}\text { High effort/reward } \\
\text { imbalance (ref. low) }\end{array}$ & $1.41(1.04-1.91)$ & $1.19(0.85-1.66)$ & $1.31(0.96-1.79)$ & $1.40(0.99-1.96)$ & $1.21(0.84-1.76)$ & $1.09(0.72-1.66)$ & $1.23(0.93-1.63)$ & $1.25(0.92-1.71)$ & $1.82(1.08-3.06)$ & $1.91(1.07-3.39)$ \\
\hline $\begin{array}{l}\text { Overcommitment } \\
\text { higher tertile (ref. } \\
\text { lower-medium tertiles) }\end{array}$ & $1.90(1.47-2.45)$ & $1.77(1.25-2.31)$ & $1.32(1.01-1.72)$ & $1.27(0.96-1.67)$ & $1.68(1.24-2.28)$ & $1.51(1.09-0.21)$ & $1.56(1.23-1.98)$ & $1.51(1.18-1.94)$ & $1.54(0.96-2.47)$ & $1.43(0.87-2.36)$ \\
\hline
\end{tabular}

${ }^{\mathrm{a}}$ OR adjusted for sex, family status, number of children, job title, smoking status, workload and all the other predictors. 
Table 3

Additive interactions between risks factors

\begin{tabular}{|c|c|c|c|c|c|c|c|c|c|}
\hline & $N$ & Poor/moderate WAI (\%) & $\mathrm{OR}^{\mathrm{a}}(95 \% \mathrm{CI})$ & $N$ & Poor sleep $(\%)$ & $\mathrm{OR}^{\mathrm{a}}(95 \% \mathrm{CI})$ & $N$ & Job dissatisfaction (\%) & $\mathrm{OR}^{\mathrm{a}}(95 \%)$ \\
\hline \multicolumn{10}{|l|}{ Interaction work schedule and ERI $I^{\mathrm{b}}$} \\
\hline High ERI+ shiftwork & 160 & 46.9 & $1.89(1.26-2.84)$ & 157 & 33.1 & $3.83(2.48-5.93)$ & 160 & 21.3 & $2.21(1.29-3.80)$ \\
\hline High ERI + daywork & 83 & 53.0 & $1.94(1.18-3.19)$ & 69 & 14.5 & $1.31(0.63-2.72)$ & 84 & 29.8 & $4.31(2.4-7.74)$ \\
\hline Low ERI+ shiftwork & 596 & 22.7 & $0.70(0.53-0.93)$ & 580 & 14.7 & $1.33(0.92-1.92)$ & 599 & 7.2 & $0.68(0.43-1.06)$ \\
\hline Low ERI + daywork & 658 & 33.3 & 1.0 & 472 & 11.4 & 1.0 & 670 & 8.4 & 1.0 \\
\hline Synergy index $(\mathrm{S})$ and $95 \% \mathrm{CI}$ & & & $2.15(0.55-8.42)$ & & & $2.12(1.37-2.73)$ & & & $0.88(0.63-1.22)$ \\
\hline \multicolumn{10}{|l|}{ Interaction ERI and overcommitment $^{\mathrm{c}}$} \\
\hline High ERI + high overcommitment & 114 & 46.5 & $2.72(1.77-4.20)$ & 107 & 31.8 & $3.06(1.82-5.13)$ & & & \\
\hline High ERI + low overcommitment & 129 & 51.2 & $3.09(2.06-4.63)$ & 119 & 23.5 & $2.21(1.32-3.69)$ & & & \\
\hline Low ERI + high overcommitment & 289 & 37.0 & $1.61(1.20-2.18)$ & 250 & 20.4 & $2.07(1.38-3.09)$ & & & \\
\hline Low ERI + low overcommitment & 965 & 25.6 & 1.0 & 802 & 11.0 & 1.0 & & & \\
\hline Synergy index (S) and 95\% CI & & & $0.62(0.52-0.74)$ & & & $0.70(0.56-0.88)$ & & & \\
\hline \multicolumn{10}{|l|}{ Interaction ERI and age } \\
\hline High ERI $+\geqslant 45 \mathrm{yr}$ & 126 & 60.3 & $3.68(2.35-5.74)$ & & & & & & \\
\hline High ERI $+<45 \mathrm{yr}$ & 350 & 44.9 & $2.25(1.68-3.01)$ & & & & & & \\
\hline Low $\mathrm{ERI}+\geqslant 45 \mathrm{yr}$ & 406 & 32.3 & $1.27(0.95-1.69)$ & & & & & & \\
\hline Low ERI $+<45$ yr & 913 & 26.7 & 1.0 & & & & & & \\
\hline \multirow[t]{2}{*}{ Synergy index (S) and 95\% CI } & & & $1.14(0.90-1.44)$ & & & & & & \\
\hline & $N$ & Cardiovascular disorders ( $\%)$ & $\mathrm{OR}^{\mathrm{a}}(95 \% \mathrm{CI})$ & $N$ & Musculoskeletal disorders (\%) & $\mathrm{OR}^{\mathrm{a}}(95 \% \mathrm{CI})$ & & & \\
\hline \multicolumn{10}{|l|}{ Interaction overcommitment and age } \\
\hline High overcommitment $+\geqslant 45 \mathrm{yr}$ & 171 & 36.3 & $5.41(3.42-8.54)$ & 171 & 57.9 & $2.61(1.75-3.90)$ & & & \\
\hline Low overcommitment $+\geqslant 45 \mathrm{yr}$ & 290 & 12.1 & $1.45(0.92-2.29)$ & 290 & 43.4 & $1.44(1.06-1.94)$ & & & \\
\hline High overcommitment $+<45 \mathrm{yr}$ & 410 & 27.1 & $3.46(2.35-5.07)$ & 410 & 42.9 & $1.52(1.14-2.04)$ & & & \\
\hline Low overcommitment $+<45 \mathrm{yr}$ & 883 & 9.4 & 1.0 & 883 & 33.7 & 1.0 & & & \\
\hline Synergy Index (S) and 95\% CI & & & $0.94(0.76-1.15)$ & & & $1.15(0.83-1.60)$ & & & \\
\hline
\end{tabular}

Note: Additive interactions between risk factors have been calculated only if main effects on the outcomes were significant.

${ }^{a}$ OR adjusted for sex, family status, number of children, job title, smoking status, workload and all the other predictors

${ }^{\mathrm{b}} \mathrm{ERI}=$ Effort $/$ Reward Imbalance.

${ }^{c}$ High overcommitment $=$ higher tertile, low overcommitment $=$ medium-lower tertile. 
smoking status, workload and the other risk factors considered, shiftwork with nights was associated with a poorer sleep, with lower levels of job dissatisfaction and gastrointestinal disorders, and with a higher work ability. Ageing workers reported more cardiovascular and musculoskeletal disorders and lower work ability. The strongest evidence was found for the associations of effort/reward imbalance and overcommitment with health. As concerns interactions, compared with additive effects, in the presence of both shiftwork with nights and effort/reward imbalance, the risk of poor sleep was higher, while in the presence of both effort/reward imbalance and overcommitment, the risk of poor sleep and poor work ability was lower. Finally, no interactions were observed between age and shiftwork, effort/reward imbalance, and overcommitment.

\subsection{Prevalence of risk factors and health outcomes}

We found a higher prevalence of poor/moderate WAI $(33.7 \%)$ than the $23.3 \%$ obtained in a sample of comparable aged healthcare workers (Costa et al., 2005), while the prevalence of musculoskeletal disorders, injuries and gastrointestinal disorders was similar. High effort/reward imbalance $(16.1 \%)$ in our sample was comparable with the $18.3 \%$ reported in a sample of 4591 Italian registered nurses (Hasselhorn et al., 2004). Overall, our findings are comparable to those observed in other Italian samples of healthcare workers.

\subsection{Associations between risk factors and health outcomes}

In our study, work ability was associated with all risk factors considered; shiftwork with nights, ageing, effort/ reward imbalance and overcommitment. Of these effort/ reward imbalance resulted as the most relevant risk. This supports the most recent conceptualization of work ability (Ilmarinen et al., 2005) suggesting that work ability is the result of an imbalance between the demands required and the resources available to the individual. A prolonged imbalance may produce excessive strain and impact on how the individual adapts to the work environment. Our findings are consistent with Ilmarinen et al. (2005) conclusion that stressful psychosocial characteristics are important factors in explaining work ability.

Age was found to be associated with lower work ability in a number of previous studies (Tuomi et al., 1997). Unexpectedly, shiftwork was not linked with low work ability, a finding not in line with previous results (Costa et al., 2005). This may be attributed, at least partially to a strong "healthy worker effect". In Italy, the possibility for less healthy and/or less satisfied ageing nursing staff to leave the workforce earlier was supported by welfare policies favouring early retirement (Camerino et al., 2006).

Shiftwork was a risk factor for poor sleep and this is consistent with earlier findings (Åkerstedt, 2003). High effort/reward imbalance and high overcommitment were associated with poor sleep (and also chronic fatigue but only in the case of high effort/reward imbalance), corroborating results obtained in previous studies (Fahlen et al., 2005). According to Geurts and Sonnentag (2006), work stress and overcommitment may increase sleep difficulties through both a physiological (i.e. sustained bodily activation) and a psychological process (ruminative thoughts). Both are at odds with the relaxed state required for good sleep and recovery.

Consistent with previous findings, job dissatisfaction, sick leave and mental disorders were associated with effort/ reward imbalance (Stansfeld and Candy, 2006; Li et al., 2005). Shiftwork was found to be protective against job dissatisfaction and gastrointestinal disorders. This last unexpected finding may be again due to the "healthy worker effect". Cardiovascular and musculoskeletal disorders were related to age, which was an expected finding considering their chronic nature, and also to overcommitment. In a review by van Vegchel et al. (2005), four out of five studies found overcommitment to be associated with a higher incidence of cardiovascular disorders, while Weyers et al. (2006) did not find any significant association between overcommitment and self-reported musculoskeletal complaints in Danish nurses. It is also interesting to note that rumination has been linked with cardiovascular and musculoskeletal disorders (Brosschot et al., 2006).

\subsection{Interactions between risk factors}

We found limited evidence concerning the additive interactions of shiftwork and work stress. Past research has reported inconsistent evidence to support the existence of a synergistic effect (Peter et al., 1999; Parkes, 1999; Frese and Semmer, 1986). However, it should be considered that in our sample shiftwork itself was not identified as a risk factor for poor health (with the exception of sleep), which may at least partly account for the few interactions we observed between shiftwork and the other risk factors.

Interestingly, the combined effect of shiftwork with nights and high effort/reward imbalance was significantly associated with a higher risk of poor sleep compared to their additive effect. This synergistic interaction seems relevant since the AP index (attributable proportion due to interaction; see Rothman, 1986), suggested that $57.1 \%$ of poor sleep cases could be attributed to the interaction between shiftwork with nights and high effort/reward imbalance.

The interaction we observed between high effort/reward imbalance and overcommitment was of an antagonistic nature, thus not supporting the theoretical assumption that the effect of effort/reward imbalance on health is higher in individuals characterized by high overcommitment (Siegrist et al., 2004). As a tentative psychological explanation, it can be hypothesized that although overcommitment is associated with low work ability, overcommitted individuals may tend to overestimate their work ability in that 
they may perceive themselves as providers of better performances in an attempt to reduce the gap between high efforts and low rewards. Regarding the other interactions we could not find plausible interpretations to explain

why the combined exposure to high effort/reward imbalance and high overcommitment might lead to a risk for poor sleep lower than the risk connected to their additive effect.

Finally, the fact that no significant interactions were observed between age on the one hand, and shiftwork, effort/reward imbalance and overcommitment on the other hand, suggests that the associations between these risk factors and poor health may be constant across age. However, the absence of an interaction between age and shiftwork is not in line with previous studies (Härmä, 1996; Costa and Sartori, 2007) that found a reduced tolerance to shiftwork in older workers.

\subsection{Study limitations and advantages}

A first limitation of this study is its cross-sectional design, restricting the possibility to draw conclusions about any causal relationships. It cannot be excluded that the relationship between the risk factors and the health outcomes may well be reversed. That is, health status may have a role in determining the level of exposure. This may apply to work stress, since individuals with lower health may perceive their work environment as more stressful because they have limited resources to cope (de Lange et al., 2005). However, even if such a reverse causation hypothesis may hold, longitudinal research provides support for the fact that work stress has a causative role on health status (Zapf et al., 1996). Health status can also determine a selection of workers into particular work schedules, in that healthier workers may be assigned to more demanding shift schemes. Such a selection may hide the true effect of shiftwork on health. To avoid bias due to selection processes, our study should be replicated using prospective designs.

Another limitation is in its reliance on self-reported measures. Bias resulting from common method variance may possibly inflate the association between the variables. A final limitation relates to the low amount of variance in the outcomes explained by the risk factors included in the regression models. Although this may limit the relevance of our findings, variance in health status accounted for by work-related factors is usually expected to be low, since health has typically a multicausal aetiology (Semmer et al., 1996; Zapf et al., 1996).

One of the main advantages of our study lies in the way interaction was assessed. The "additive interaction" approach is recommended by epidemiologists to assess interaction between risk factors when binomial logistic models are used (see Hallqvist et al. (1996) for an in-depth discussion). We recommend other studies employ this methodology.

\subsection{Conclusion}

In conclusion, our study failed to find supportive evidence for the hypothesized interactive health effects of shiftwork, work stress and ageing among healthcare workers. The main finding of our study relates to the adverse effects that a stressful psychosocial environment may have for the health and well-being of healthcare workers, and to the need for healthcare organizations to arrange work settings in a way that is consistent with the goal of providing a better balance between the demands required to the workers and the rewards they receive in turn. As a first indication, it seems that interventions to reduce work stress may be beneficial to all workers, irrespective of age. However, further research should focus on whether rewards may function differently according to age in the way they compensate for the efforts produced.

\section{References}

Adams, J.S., 1965. Inequity in social exchange. Adv. Exp. Soc. Psychol. $62,335-343$.

Åkerstedt, T., 2003. Shift work and disturbed sleep/wakefulness. Occup. Med. 53, 89-94.

Bakker, A.B., Killmer, C.H., Siegrist, J., Schaufeli, W.B., 2000 Effort-reward imbalance and burnout among nurses. J. Adv. Nurs. 31, 884-891.

Barton, J., Spelten, E., Totterdell, P., Smith, L., Folkard, S., Costa, G., 1995. The standard shiftwork index: a battery of questionnaires for assessing shiftwork-related problems. Work Stress 9, 4-30.

Beatty, P.T., Burroughs, L., 1999. Preparing for an aging workforce: the role of higher education. Educ. Gerontol. 25, 595-611.

Brosschot, J.F., Gerin, W., Thayer, J.F., 2006. The perseverative cognition hypothesis: a review of worry, prolonged stress-related physiological activation, and health. J. Psychosom. Res. 60, 113-124.

Camerino, D., Conway, P.M., Van Der Heijden, B.M.J.I., Estryn-Behar, M., Consonni, D., Gould, D., Hasselhorn, H.-M., The Next-Study Group, 2006. Low perceived work ability, ageing and intention to leave nursing: a comparison among ten European countries. J. Adv. Nurs. 56, 542-552.

Conway, P.M., 2005. Working condition, work-related health and intent to leave the profession among Italian qualified nurses: results from the European Nurses Early Exit Study. Doctoral Thesis, University of Milan.

Costa, G., 2003. Factor influencing health and tolerance to shift work. Theor. Issues Ergon. Sci. 4, 263-288.

Costa, G., Sartori, S., 2007. Ageing, working hours and work ability. Ergonomics 50, 1914-1930.

Costa, G., Sartori, S., Bertoldo, B., Olivato, D., Antonacci, G., Ciuffa, V., Mauli, F., Goedhard, W., Ilmarinen, J., 2005. Work ability in health care workers. In: Costa, G., Goedhard, W., Ilmarinen, J. (Eds.), Assessment and Promotion of Work Ability, Health and Well-Being of Ageing Workers. Elsevier, Amsterdam, pp. 264-269.

de Lange, A.H., Taris, T.W., Kompier, M.A.J., Houtman, I.L.D., Bongers, P.M., 2005. Different mechanisms to explain the reversed effects of mental health on work characteristics. Scand. J. Work Environ. Health 31, 3-14.

Demerouti, E., Geurts, S.A.E., Bakker, A.B., Euwema, M., 2004. The impact of shiftwork on work-home conflict, job attitudes and health. Ergonomics 47, 987-1002.

Fahlen, G., Knutsson, A., Peter, R., Akerstedt, T., Nordin, M., Alfredsson, L., Westerholm, P., 2005. Effort-reward imbalance, sleep disturbances and fatigue. Int. Arch. Occup. Environ. Health 13, 1-8. 
Frese, M., Semmer, N., 1986. Shiftwork, stress, and psychosomatic complaints: a comparison between workers in different shiftwork schedules, non-shiftworkers, and former shiftworkers. Ergonomics 29, 99-114.

Geurts, S.A.E., Sonnentag, S., 2006. Recovery as an explanatory mechanism in the relation between acute stress reactions and chronic health impairment. Scand. J. Work Environ. Health 32, 482-492.

Haider, M., Kundi, M., Koller, M., 1981. Methodological issues and problems in shiftwork research. In: Johnson, L., Tepas, D., Colquhoun, P., Colligan, M. (Eds.), Biological Rhythms, Sleep and Shiftwork. Spectrum, Jamaica, NY, pp. 145-163.

Hallqvist, J., Ahlbom, A., Diderichsen, F., Reuterwall, C., 1996. How to evaluate interaction between causes: a review of practices in cardiovascular epidemiology. J. Intern. Med. 239, 377-382.

Härmä, M., 1996. Ageing, physical fitness and shiftwork tolerance. Appl. Ergon. 27, 25-29.

Härmä, M., 2006. Work hours in relation to work stress, recovery and health. Scand. J. Work Environ. Health 32, 502-514.

Hasselhorn, H.M., Tackenberg, P., Mueller, B., 2003. Working Conditions and Intent to Leave the Profession Among Nursing Staff in Europe. Working Life Research Report 7. National Institute for Working Life, Stockholm.

Hasselhorn, H.M., Tackenberg, P., Peter, R., Next-Study Group, 2004. Effort-reward imbalance among nurses in stable countries and in countries in transition. Int. J. Occup. Environ. Health 10, 401-408.

Hosmer, D.W., Lemeshow, S., 1992. Confidence interval estimation of interaction. Epidemiology 3, 452-456.

Ilmarinen, J., 1999. Ageing Workers in European Union. Finnish Institute of Occupational Health, Helsinki.

Ilmarinen, J., Tuomi, K., Seitsamo, J., 2005. New dimensions of work ability. In: Costa, G., Goedhard, W., Ilmarinen, J. (Eds.), Assessment and Promotion of Work Ability, Health and Well-Being of Ageing Workers. Elsevier, Amsterdam, pp. 3-7.

Ingersoll, G.L., Olsan, T., Drew-Cates, J., DeVinney, B.C., Davies, J., 2002. Nurses' job satisfaction, organizational commitment, and career intent. J. Nurs. Admin. 32, 250-263.

Kalilani, L., Atashili, J., 2006. Measuring additive interaction using odds ratios. Epidemiol. Perspect. Innov. 3, 5.

Lazarus, R., Folkman, S., 1984. Stress Appraisal and Coping. Spinger, New York.

Li, J., Yang, W., Cheng, Y., Siegrist, J., Cho, S., 2005. Effort-reward imbalance at work and job dissatisfaction in Chinese healthcare workers: a validation study. Int. Arch. Occup. Environ. Health 78, 198-204.

McVicar, A., 2003. Workplace stress in nursing: a literature review. J. Adv. Nurs. 44, 633-642.

Monk, T.H., 1988. Coping with the stress of shiftwork. Work Stress 2, $169-172$.

Muecke, S., 2005. Effects of rotating night shifts: literature review. J. Adv. Nurs. 50, 433-439.

Olsson, K., Kandolin, I., Kauppinen-Toropainen, K., 1990. Stress and coping strategies of three-shift workers. Trav. Hum. 53, 175-188.

Parkes, K.R., 1999. Shiftwork, job type, and the work environment as joint predictors of health outcomes. J. Occup. Health Psychol. 4, 256-268.
Peter, R., Alfredsson, L., Knutsson, A., Siegrist, J., Westerholm, P., 1999. Does a stressful psychosocial work environment mediate the effects of shift work on cardiovascular risk factors? Scand. J. Work Environ. Health 25, 376-381.

Poissonnet, C.M., Véron, M., 2000. Health effects of work schedules in healthcare professions. J. Clin. Nurs. 9, 13-23.

Rothman, K.J., 1986. Modern Epidemiology. Little, Brown, Boston.

Semmer, N., Zapf, D., Greif, S., 1996. "Shared job strain": a new approach for assessing the validity of job stress measurement. J. Occup. Organ. Psychol. 69, 293-310.

Siegrist, J., 1996. Adverse health effects of high effort-low reward conditions at work. J. Occup. Health Psychol. 1, $27-43$.

Siegrist, J., Peter, R., 1996. Measuring Effort-Reward Imbalance at Work: Guidelines. Institut für Medizinische Soziologie, Düsseldorf.

Siegrist, J., Starke, D., Chandola, T., Godin, I., Marmot, M., Niedhammer, I., Peter, R., 2004. The measurement of effort-reward imbalance at work: European comparison. Soc. Sci. Med. 58, 1483-1499.

Simon, M., Kümmerling, A., Hasselhorn, H.M., 2004. Work-home conflict in the European nursing profession. Int. J. Occup. Environ. Health 10, 384-391.

Smith, C.S., Robie, C., Folkard, S., Barton, J., Macdonald, I., Smith, L., Spelten, E., Totterdell, P., Costa, G., 1999. A process model of shiftwork and health. J. Occup. Health Psychol. 4, 207-218.

SPSS 12.01, 2003. SPSS Inc., Chicago, IL, USA.

Stansfeld, S., Candy, B., 2006. Psychosocial work environment and mental health. Scand. J. Work Environ. Health 32, 443-462.

StataCorp., 2005. Stata Statistical Software: Release 9. College Station, TX: StataCorp LP.

Taimela, S., Laara, E., Malmivaara, A., Tiekso, J., Sintonen, H., Justen, S., Aro, T., 2007. Self-reported health problems and sickness absence in different age groups predominantly engaged in physical work. Occup. Environ. Med. 64, 739-746.

Taylor, E., Briner, R.B., Folkard, S., 1997. Model of shiftwork and health: an examination of the influence of stress on shiftwork theory. Hum. Factors 39, 67-82.

Tuomi, K., Ilmarinen, J., Seitsamo, J., Huuhtanen, P., Martikainen, R., Nygard, C.H., Klockars, M., 1997. Summary of the Finnish research project (1981-1992) to promote the health and work ability of ageing workers. Scand. J. Work Environ. Health 23 (Suppl. 1), 66-71.

Tuomi, K., Ilmarinen, J., Jahkola, A., Katajarinne, L., Tulkki, A., 1998. Work Ability Index, second ed. Finish Institute of Occupational Health, Helsinki.

van Vegchel, N., de Jonge, J., Meijer, T., Hamers, J.P.H., 2001. Different effort constructs and effort-reward imbalance: effects on employee well-being in ancillary health care workers. J. Adv. Nurs. 34, 128-136.

van Vegchel, N., de Jonge, J., Bosma, H., Schaufeli, W., 2005. Reviewing the effort-reward imbalance model: drawing up the balance of 45 empirical studies. Soc. Sci. Med. 60, 1117-1131.

Weyers, S., Peter, R., Boggild, H., Jeppensen, H.J., Siegrest, J., 2006. Psychosocial work stress is associated with poor self-rated health in danish nurses: a test of the effort-reward imbalance model. Scand. J. Caring Sci. 20, 26-34.

Zapf, D., Dormann, C., Frese, M., 1996. Longitudinal studies in organizational stress research: a review of the literature with reference to methodological issues. J. Occup. Health Psychol. 1, 145-169. 